Implementation:

- Six week pilot with two volunteers

- Volunteers attended morning handovers, working 07.15 13.15 one day a week

- Reflective feedback was gathered from ward volunteers.

Evaluation:

Face-to-face interviews with volunteers and staff.

Conclusion Early indications:

- Volunteers made positive contributions and integrated well into the wards

- Volunteers were involved in emotional support and practical tasks, allowing staff more time with patients and families

- Quicker responses to patients' needs

- Volunteers felt empowered

- The project was a professional development opportunity for the Volunteer Champions.

Future plans: The evaluation will help us refine a more fulfilling role for ward volunteers contributing to an enhanced patient and family experience.

\section{P-279 INNOVATIVE INVOLVEMENT OF VOLUNTEERS IN CLINICAL ROLES IN A HOSPICE SETTING}

Karen Filsell, Dot Partington, Duncan Brown, Vicky Hill, Yvonne Whitehouse. St Columba's Hospice, Edinburgh, UK

\subsection{6/bmjspcare-2018-hospiceabs.304}

Background Volunteers are vital to hospices in helping to deliver high quality care. As a hospice with over 600 volunteers we included in our current five year strategy a commitment to 'recruit the right volunteers into the right roles'.

Method Historically volunteer teams were principally under the management of the Volunteer Services team. Through reviewing their roles, responsibility and the management structure, the volunteers were integrated into existing clinical teams. Based on the review a number of changes were implemented:

- The role of the volunteers in our new Day Care Service model became integrated into the clinical team structure. This included joint educational programme for staff and volunteers and management of the volunteer team was adopted by the manager of Day Therapy Services staff

- The role of volunteers was extended in the Clinical Governance team where our volunteers have become essential members of the team and are taking active part in leading on and delivering specific projects within the hospice

- We involve expert volunteers into the hospice on a more ad hoc basis. A consultant radiologist was recruited as a volunteer to purchase an ultrasound machine, provide education for staff and oversee the implementation and use of this new equipment.

Results

- Our volunteers are now fully integrated into the different teams they work with rather than seen as belonging to the Volunteer Services team

- Through joint education as well as staff knowing the volunteers better there is more confidence around their role and what they can contribute
- The volunteers being supported on the ground and within the team by the team manager enables them to contribute fully within their role.

Conclusion Working to 'recruit the right volunteers into the right roles' has challenged staff in the hospice to think more creatively about the roles that they offer to volunteers.

\section{P-280 CLINICAL NURSE SPECIALISTS IN DEVELOPMENT- GROWING YOUR OWN}

Christine Goodwin, Sharon Hudson, Lisa Kennedy. Birmingham St Mary's Hospice, Birmingham, UK

\subsection{6/bmispcare-2018-hospiceabs.305}

Background Birmingham St Mary's Hospice Community Team is a large urban Community Palliative Care Service in Birmingham. The Clinical Nurse Specialist Team are Band 7 Nurses and have responsibility for caseload management, clinical effectiveness and leadership. They support a 24 hour on call service and delivery of the hospice education programme. In recent years recruitment to these roles has been difficult. This aligns with the national picture of a current shortfall of $10 \%$ in the nursing workforce.

The hospice specifies at least degree level education, two years' experience at Band 7 in palliative care or relevant specialty and postgraduate education in palliative care as core to the role. The role is changing; with a need to understand palliative care beyond cancer, to work within a changing health landscape and to have advanced practice skills such as NMP. In recruitment, we were seeing nurses with the right values base and with some relevant experience but without the experience or qualifications to fulfil the role.

Method The hospice developed a Band 6 to 7 Competency Programme based broadly on the Macmillan Competency Framework (2) for Nurses but tailored to a broad palliative care approach.

- Six month programme of mentored support, education and experiential learning

- Sage \& Thyme Certification

- European Certificate in Palliative Care

- Competency Programme and Reflection; Expert practice, leadership and consultancy, education and clinical effectiveness. This can then be utilised for re-validation.

Outcomes

- Nine nurses recruited to the programme over five years

- From a broad range of backgrounds including ITU, district nursing and internally. This has enabled a positive approach to integration with primary and secondary care and supported positive cultural change

- Eight have completed and were successful in transition to Band 7 , seven are still in post.

\section{P-281 LEARNING AND SHARING TO TRANSFORM CARE}

Ruth Auton. LOROS, Leicester, UK

\subsection{6/bmjspcare-2018-hospiceabs.306}

The Florence Nightingale Fellowship award travel scholarships to nurses and midwives to travel and learn about nursing in 